\title{
Heavy metal toxicity and the aetiology of glaucoma
}

\author{
Sarath Vennam ${ }^{1} \cdot$ Stelios Georgoulas ${ }^{1,2}$ - Anthony Khawaja ${ }^{1,2}$ - Sharon Chua ${ }^{1}$ Nicholas G. Strouthidis ${ }^{1,2}$. \\ Paul J. Foster $\mathbb{D}^{1,2}$
}

Received: 1 October 2019 / Accepted: 6 October 2019 / Published online: 19 November 2019

(c) The Author(s), under exclusive licence to The Royal College of Ophthalmologists 2019

\begin{abstract}
Despite recent advances, our understanding of the aetiological mechanisms underlying glaucoma remains incomplete. Heavy metals toxicity has been linked to the development of neurodegenerative diseases and various ocular pathologies. Given the similarities in pathophysiology between glaucoma and some neurodegenerative disorders, it is plausible that heavy metal toxicity may play a role in the development of glaucoma. Heavy metal exposure may be occupational, or through water or dietary contamination. In this report, we review mechanisms for systemic and neurotoxicity for arsenic, cadmium, chromium, cobalt, lead, mercury, and manganese, and weigh the evidence for an association between glaucoma and the accumulation of heavy metals either in ocular tissues or in the central nervous system.
\end{abstract}

\section{Introduction}

Glaucoma is a progressive, irreversible optic neuropathy in which there is damage to retinal ganglion cell axons anterior to the lamina cribrosa resulting in structural changes to the optic nerve head, causing an excavated appearance, which results in visual field loss [1]. Glaucoma is the second leading cause of blindness globally. It has been estimated that, by 2020, 80 million people will suffer from glaucoma [2]. Most cases are classified as "primary", with "secondary" disease, in which primary denotes an absence of an identifiable cause or mechanism that could result in either intermittent or sustained elevation of intraocular pressure (IOP). Secondary glaucoma accounts for around $10-15 \%$ of cases globally. The most common form of glaucoma, primary open angle glaucoma (POAG), is typically a bilateral, asymmetrical, chronic, progressive optic neuropathy. Progression may be retarded in many cases by reduction of IOP $[1,3]$. The benefit of IOP reduction in glaucoma has been

These authors contributed equally: Sarath Vennam, Stelios Georgoulas

Paul J. Foster

p.foster@ucl.ac.uk

1 UCL Institute of Ophthalmology, 11-43 Bath Street, London EC1V 9E, UK

2 Glaucoma Service, Moorfields Eye Hospital, City Road, London EC1V 2PD, UK demonstrated in many clinical trials, which have proven and quantified the benefit of IOP reduction in both high and normal pressure variants of POAG [3, 4]. A recent publication by our group confirms a major role for genetically influenced elevation of IOP in the aetiology of POAG [5]. Other risk factors for POAG include older age, African or Caribbean ancestry, and myopia [6, 7]. Although the role of genes in the development of POAG has not been fully determined, linkage studies have identified abnormalities in MYOC, OPTN, and WDR36 as potentially causative in glaucoma.

\section{Association between glaucoma and other known neurodegenerative conditions}

Glaucoma is usually regarded as an isolated neuropathy of the optic nerve, although degenerative changes have been identified along the visual pathway. Glaucoma may cause atrophy of the lateral geniculate nucleus (LGN) laminae, dendrite pathology in the LGN, and reduced visual cortex thickness and metabolic activity $[8,9]$. In rodent studies, it has been suggested that changes can be detected in the LGN before significant axonal loss occurs [5, 10]. Damage to retinal ganglion cells (RGC) axons causes antegrade degeneration, leading to changes in the optic nerve, chiasm, and LGN. Retrograde degeneration leads to loss of RGCs [11].

Glaucoma shares some common characteristics with other neurodegenerative diseases such as Alzheimer's 
disease (AD) [12] and Parkinson's and amyotrophic lateral sclerosis (ALS) [13]. All these diseases involve loss of specialized neuron subsets, as does glaucoma. While glaucoma is characterised by retinal ganglion cell axonopathy, in Alzheimer's the focus for damage is the hippocampus, whereas in Parkinson's damage occurs in the dopaminergic cells in the substantia nigra, and ALS, by damage to upper and lower motor neurons [14]. The incidence of all these conditions increases with age, implying that cumulative exposure to an external factor likely plays a role in the development of these diseases. Both AD and glaucoma exhibit loss of RGCs [15]. Furthermore hyperphosphorylated tau protein is present in $\mathrm{AD}$ and has been reported in glaucoma. Beta amyloid has been identified in the retina of animals with glaucoma [12, 16-18].

Carreras has hypothesised that ALS and glaucoma may share similar pathophysiological pathways. In both conditions, there are pathological abnormalities in the circulation of central-nervous-system fluids (namely, aqueous humour and cerebrospinal fluid (CSF). In ALS, both CSF and the aqueous humour have a low concentration of calcium as compared with the concentration in serum [19, 20]. Signal transmission in the axons of RGCs is an energy intensive process. Numerous astrocytes around optic nerve contain giant mitochondria, which provide the necessary adenosine triphosphate. It has been suggested that damage to these astrocytes results in an energy deficiency, thereby leading to dysfunction in RGC axons and, subsequently, apoptosis [21]. Carreras's hypothesis proposes that, in glaucoma, the low calcium concentration of aqueous humour gives rise to ionic stress in astrocytes and premature apoptosis. A proposed mechanism of damage, similar to that described in glaucoma, is that of reduced circulating calcium in CSF leading to astrocyte damage and early apoptosis in upper and lower motor neurons in ALS [14, 19, 20, 22]. Furthermore, evidence for genetic overlap in glaucoma and ALS has been described. Optineurin is a protein expressed in the trabecular meshwork, retina, and brain and may have neuroprotective properties. Optineurin mutations confer an increased risk of POAG developing at lower levels of IOP, and have also been identified in hereditary ALS. Maruyama et al. reported six patients with ALS and, by conducting homozygosity mapping, they identified two patients to have a deletion of exon 5 in the optineurin (OPTN) gene [23, 24].

\section{The role of heavy metals in neurodegenerative diseases}

Exposure to heavy metals occurs from a variety of sources, including industrial and transport activities, as well as in the home. There may be contamination in the air, food, water, and soil. Exposure to heavy metals in the atmosphere occurs through fine dust pollutants generated from industries. Ground contamination potentially leads to polluted food and water supplies [25].

\section{$A D$ and heavy metals}

An aetiological role for heavy metals in $\mathrm{AD}$ has been suspected, but remains unproven. The serum levels of lead, cadmium, mercury, and arsenic were studied in 89 patients with $\mathrm{AD}$ and in 118 cognitively normal individuals in South Korea. The levels of these metals were not significantly different in normal and AD individuals and no correlation was suggested between the levels of these metals and the cognitive ability in AD [26]. Strong evidence implicating metals such as lead, mercury, and arsenic is lacking; only cadmium has been identified as a potential factor in the development of AD. Research has linked cadmium with neurotoxicity leading to morphological changes in cerebral cortical neurons, cell death, and lower cognitive scores [27-29]. Cadmium accumulation may contribute to the development of amyloid- $\beta$ plaques and neurofibrillary tangles, key characteristics of the AD pathogenesis [30, 31]. Min et al. found a significant association between blood cadmium levels and AD. In this study, the mortality data and blood cadmium levels of 4064 participants in the US Third National Health and Nutrition Examination Survey and the Linked Mortality File were analysed. It was found that there was an almost fourfold increased risk of death among those with levels $>0.6 \mu \mathrm{g} / \mathrm{L}$ and an almost twofold increase among those with blood cadmium levels $0.4-0.6 \mu \mathrm{g} / \mathrm{L}$, compared with those with blood cadmium levels $\leq 0.3 \mu \mathrm{g} / \mathrm{L}$ [32]. Jang et al. explored potential causes for increased cadmium exposure and implicated fish eating as a risk factor for increased cadmium intake and therefore increased risk of developing $\mathrm{AD}[33,34]$.

\section{The role of lead and cadmium in ALS}

In a study examining 184 cases of ALS and 194 controls, a twofold higher blood lead level was associated with a doubling of risk of ALS [22, 35]. In another study, the concentration of metals in blood and CSF in 17 people with ALS and ten controls found significantly higher CSF lead and cadmium levels in ALS patients compared with controls. Paradoxically, blood levels did not differ between cases and controls [36]. Bar-Sela et al. examined a case of a battery factory worker, who died of ALS and suggested that cadmium exposure was the cause of his ALS [37]. A case control study, however, did not find evidence to support a role for lead or cadmium in the development of ALS, and instead, found lower mean levels of mercury and cadmium in the CSF of ALS patients when compared with controls [38]. A significantly higher risk of developing ALS among 
those with high bone lead levels has also been suggested $[39,40]$. It has been suggested that lead interferes with copper metabolism in astroglia, leading to the formation of free radicals, resulting in oxidative stress [39, 41-43].

\section{Parkinson's disease (PD) and heavy metals}

PD is the second most common neurodegenerative disorder after $\mathrm{AD}$, and is characterised by the presence of Lewy bodies in the living neurons [44]. Kuhn et al. [45] reported the development of symptoms consistent with Parkinson's in the majority of workers exposed to lead sulfate batteries for up to 3 decades [45]. Coon et al. [46] explored the relationship between PD symptoms and tibial and calcaneal bones lead levels of 121 PD patients and 414 controls. Among individuals in the highest quartile of inferred lifetime lead exposure, the risk of developing PD was double that of those in the lowest quartile [46]. Similar results regarding long-term lead exposure and risk of development of PD has been shown in studies by Gorell et al. [47] and Wisskopf et al. (2010). Gorell et al. also showed an elevated PD risk in a population from the metropolitan Detroit area when lifetime exposure to manganese exceeded 20 years [47]. Perl and Olanow reported damage of the globus pallidus in prolonged exposure to manganese in patients and primates. This previous observation is at odds with the preservation of the globus pallidus and the degeneration of the dopamine neurons seen in PD [48].

\section{Heavy metals in the pathogenesis of multiple sclerosis (MS)}

MS is an immune-mediated chronic inflammatory disease of the central nervous system. Exposures to heavy metals can lead to toxicity and oxidative stress. A case control study compared blood lead levels in 29 MS patients and 29 healthy controls, and found that the risk of MS increased $20 \%$ per $1 \mu \mathrm{g} / \mathrm{L}$ increment of blood lead level [49]. Glutathione-S-transferases are involved in combating oxidative stress and also in metal biotransformation. Aliomrani et al. investigated the correlation of GSTM1 genetic polymorphisms in MS patients in Iran and explored the possible link with blood concentration of arsenic and cadmium. The frequency of GSTM1 polymorphisms did not differ between cases and controls. Blood arsenic and cadmium concentrations were considerably higher in MS patients in comparison with healthy individuals. The GSTM1 null genotype was associated with high cadmium level in MS patients. The same group reported that lead levels did not differ between MS and healthy individuals, but were higher in male than female MS patients. Lead and cadmium were also found to be higher in smokers, suggesting the potential for an enhanced susceptibility to cadmium toxicity, especially in relapsing-remitting MS patients who smoke [50].

\section{The heavy metals in glaucoma pathology}

The Chennai Glaucoma Study compared the data of 3924 patients from rural South India with 3850 patients from urban Chennai and showed the prevalence of POAG to be more than double in the urban population (1.6-3.5\%, respectively) [51]. Another study from South India, which studied 2790 patients in a rural cohort and 934 in an urban cohort, also showed a twofold greater glaucoma prevalence in the urban population, with rates of 1.6 and $4 \%$, respectively [52]. Proximity to roads and railways is directly correlated to environmental heavy metal levels in soil [53]. Heavy metal pollutant levels in and on food crops are generally higher in urban areas, compared with those from rural areas [54]. These observations might offer an explanation for the higher rates of POAG in cities. Apeagyei et al. examined cars, tyres, and road dust in Massachusetts, finding higher concentrations of iron, calcium, titanium, and potassium on urban roads that, through rainwater runoff, may form localised resuspended particulate matter [55]. Another group investigated metal levels in traffic and parking areas, residential areas, mixed residential/commercial areas, and suburban areas in Jeddah, Saudi Arabia, and compared these with a rural area. Heavy metals were most abundant in traffic areas and lowest in rural areas. The group reported that environmental cadmium, arsenic, lead, zinc, and copper were significantly elevated, while manganese, vanadium, cobalt, nickel, and chromium were moderately raised [56]. Thus, it is possible to hypothesize a link between greater exposure to heavy metals in urban areas and greater prevalence of glaucoma in towns and cities. Although further investigation is required, if heavy metals toxicity were associated with the development of glaucoma, this would offer a novel, modifiable risk factor.

\section{Cobalt and chromium toxicity}

Cobalt is neurotoxic and can cause optic neuropathy and retinopathy [57]. Historically, cobalt exposure was seen in industrial workers, when they were exposed to tungsten and cobalt dust. More recently, pathological blood cobalt levels in patients with metal hip replacements have been reported. This manifests with systemic abnormalities including cardiomyopathy, pulmonary fibrosis, hypothyroidism, and dermatitis. In addition, neurological symptoms such as tremor, cognitive decline, depression, sensorineural hearing loss, peripheral neuropathy, and toxic retinopathy have been documented [58, 59]. Similar to other heavy metals, cobalt can cause oxidative stress, resulting in damage of DNA and 
early apoptosis $[57,59,60]$. $\mathrm{Ng}$ et al. reported a case of joint replacement-related chorio-retinopathy, with patchy degeneration of the photoreceptor-retinal pigment epithelium (RPE) complex seen on optical coherence tomography, and hypofluorescent lesions on indocyanine green angiography [61]. Approximately 2.9 million joint prostheses are implanted each year globally. Even if these constitute a small increase in risk, the numbers involved could make this an important risk factor [62].

A more recent study compared visual function and retinal electrophysiology in 33 patients with articular surface replacements (ASR - a recalled chromium-cobalt prosthesis), with 33 control patients. Patients with ASRs had a significantly higher blood cobalt level, showed significantly longer visual-evoked potential latency and greater electroretinography mixed rod-cone b-wave amplitudes, although the visual acuity was not statistically different in the two groups [63].

Apostoli et al. administered intravenous cobalt alone, chromium alone, or a combination of the two in New Zealand white rabbits. Although chromium did not have a specific effect on the rabbits, cobalt caused optic nerve damage and the loss of cochlear hair cells. Higher doses of cobalt resulted in RGC loss and optic neuropathy in a pattern related to the dose and duration of exposure. Cobalt passed the blood aqueous barrier when administered intravenously in this study [57]. Other studies have shown similar toxic effects of cobalt on the eye, such as optic nerve atrophy, however the concentrations required to produce such effects as reported by Apostoli et al. were 1/80th of the previous studies [64]. Apostoli et al. also showed that there was RGC axonal oedema and thinning of myelin under light microscopy. They proposed that these changes result from cobalt-induced oxidative stress on ganglion cell mitochondria and subsequent apoptosis. This study, as well as one by Carelli et al., draw upon similarities between optic neuropathies seen in mitochondrial diseases and cobalt-induced optic neuropathy [57, 65]. Given the histological findings shown by Apostoli et al. and the visual disturbance and neuropathy in humans with cobalt exposure identified in these studies, it is plausible that cobalt may have a role in the development of glaucomatous changes in the optic nerve.

\section{Cadmium toxicity}

Cadmium is a toxic metal that has been rated as the seventh most hazardous element on the United States Environmental Protection Agency's priority list of hazardous substances [66]. Cadmium is used in the battery, dyes, and plastics industries and exposure to it is a potential risk for employees in these industries. Cadmium exposure to the general population occurs during the burning of waste, contamination of soil, and fish eating [66-68]. Cadmium has a number of toxic biochemical effects; it damages the endothelium of blood vessels, causes intracellular oxidative stress, inhibits the $\mathrm{Na} / \mathrm{K}$ pump, as well as impairing calcium homoeostasis [66, 69-71]. Vascular damage can lead to a number of systemic disorders, such as hypertension, renal damage, and vascular dysfunction, which is of potential importance, given the role of vascular dysfunction in glaucoma [72]. Cadmium interferes with calcium homoeostasis by acting as a competitive inhibitor, affecting action potential transmission [69, 70, 73]. Cadmium causes oxidative stress, particularly in the cells of the retina and neurons ([57], [74]), possibly through reduced glutathione levels, resulting in the production of free radical oxygen molecules, which damage lipid membranes and DNA, thereby suggesting a possible route to increased risk of glaucoma [57, 74-76]. Lee et al. identified a connection between cadmium toxicity and open angle glaucoma in men [66, 71]. Lee et al.'s study of 5198 individuals examined the potential relationship between open angle glaucoma and lead, cadmium, and mercury. Blood cadmium levels were significantly higher in men with low pressure open angle glaucoma (baseline IOP lower than or equal to $15 \mathrm{mmHg}$ ), as compared with men in the non-glaucomatous group.

It has been hypothesized that impaired vascular autoregulation plays a significant role in the pathophysiology of normal tension glaucoma (NTG) [77]. An association between NTG and systematic diseases including migraine and primary vascular dysregulation has been shown [78]. The imaging of blood flow in the optic nerve of NTG patients has suggested the dysfunction of vascular autoregulation mechanism. However, the actual mechanism of damage to the optic nerve is not clearly understood [78]. Building on Prozialeck's review, Lee et al. suggested that the role of cadmium in vascular damage may be most pivotal in the development of NTG, and specifically, did not implicate cadmium in glaucoma with IOPs greater than 15 mmHg [66, 71]. The average daily consumption of cadmium in Tokyo is double that of the cadmium consumed in Dallas [79]. This is interesting considering that $95 \%$ of OAG seen in Japan is normal pressure disease [80]. Although it is not possible to confirm that this high proportion of normal pressure glaucoma is solely caused by cadmium, it warrants further study.

\section{Lead toxicity}

Lead is widely used in the weapons, paints, and battery industries, and was previously widely used in water pipes and food packaging. In these uses, the main form exists in the +2 oxidation state. Divalent lead ions are colourless in solution and are hydroxylated to $\left[\mathrm{Pb}_{4}(\mathrm{OH})_{4}\right]^{4+}$ in which the hydroxyl ions act as a ligands. These ligands bind to 
membranes, interact with proteins, and alter the structure of DNA. Lead absorption is inversely proportional to age, with younger brains absorbing more lead, due to an immature blood-brain barrier [81-84].

Lead levels wax and wane between different tissues at different ages. The main reservoir of lead in the body is in bone, in which turnover is generally slow, being in the region of years to decades. Lead sequestered in bone is believed to pose no significant risk of toxicity but is barometer of long-term exposure. Bone turnover is reduced by exercise and higher levels of dietary calcium. Egress of lead from bone is accelerated during rapid growth in childhood, pregnancy, lactation, the menopause and associated osteoporosis. Blood lead levels are sensitive to short-term exposure (over the previous 30 days). Blood lead also provides an index of lead exiting the bone, but these two measures are only weakly correlated. It has been estimated that between 40 and $70 \%$ of blood lead is derived from endogenous stores in the bone. Chronic low-level lead exposure is believed to be common, and the most sensitive measure of long-term exposure is x-ray fluorescence examination of tibial or calcaneal bone. Bone lead measures correlate most strongly with a range of health outcomes in early and later life [85].

Lead has been widely used in an organic, fat-soluble form, tetraethyl lead. In this compound, lead exists in the +4 oxidation state. Tetraethyl lead was widely used as an additive in gasoline (petrol) and kerosene (jet fuel). This decomposes with exposure to sunlight. Toxic effects are different from those of inorganic lead compounds and seem to have their actions as a consequence of the behaviour of the whole molecule, not solely the metallic ion. Because of its highly lipophilic nature, tetraethyl lead passes rapidly through the blood-brain barrier readily and accumulates in the limbic forebrain, frontal cortex, and hippocampus. It can cross the blood-placental barrier from 12 weeks of gestation. Chronic effects of tetraethyl lead include poor neurobehavioral scores in tests of manual dexterity, executive ability, and verbal memory [86].

The mechanism for lead reaching the neural retina has not been fully determined. It enters neurons via calcium channels in competition with calcium ions, and although not specific to the retina, is transported to the cell soma via retrograde axonal transport [87-91]. Lead competitively inhibits the entry of calcium into cells and reduces endplate action potential, impeding nervous transmission [82].

Ekinci linked occupational lead exposure to pathological changes in the eye. Fifty battery factory workers were compared with a control of 20 healthy participants. The subjects underwent eye examinations using spectral domain optical coherence tomography and best-corrected visual acuity (BCVA) tests. After stratification into groups based on blood lead level, it was found that occupational lead exposure was associated with lower macular, choroidal, and retinal nerve fibre thicknesses [92, 93]. A second study examined the eyes of cadavers and analysed heavy metal concentrations in various parts of the eye. The greatest lead accumulation was seen in the choroid and RPE [88]. Lead is thought to hinder myelinogenesis in the optic nerve and cause opacification of the lens, due to disruption of protein structure [94]. Schaumberg et al. examined 795 participants and implicated lead as an "unrecognised risk factor" in cataract development [95].

Data from the Korean National Health and Nutrition Examination Survey (KNHANES) did not identify any association between serum lead levels and open angle glaucoma in this cross-sectional study of 5198 people $[71,96]$. Conversely, hair lead levels were significantly higher in 98 POAG patients the glaucoma group when compared with 245 controls [71, 96]. Given the recognized pathological effects of lead on the nervous system and eye as well as the current inconclusive data, a further studies of the possible link between lead and POAG is necessary.

\section{Mercury toxicity}

Mercury, commonly existing as elemental mercury and also methylmercury, is a highly toxic metal. It is used in heavy industries and it can be found as a contaminant in food. Methylmercury is highly lipophilic and passes into the brain easily. Methylmercury acts intracellularly, reacting with sulfur containing proteins, such as cysteine and methionine containing groups [69, 70, 73]. Mercury depletes plasma protein antioxidant stores, as well as causing mitochondrial damage, oxidative stress, and increased glutamate in the extracellular space, ultimately leading to neuronal damage [92, 93, 97, 98].

Although data from KNHANES have shown no links between blood mercury levels and POAG, other studies suggest that an association may exist [71]. Mela et al. fed freshwater fish varying amounts of methylmercury and analysed the ultrastructure of their eyes. This study showed toxic accumulation in the retina and damage to the photoreceptors. The structural changes in the fish photoreceptors (both rods and cones) were proportional to the dose of methylmercury [99].

A case of mercury optic neuropathy has been reported in a 36-year old who also developed multiple peripheral neuropathies. Both maculae showed "granular-type" changes. The patient consumed a large amount of fish, in particular red snapper which, when tested, was found to contain 20 times the recommended maximum level of mercury. Blood tests revealed raised blood mercury levels. Given the patient's history and examination findings, the patient was diagnosed with bilateral optic neuropathy secondary to mercury poisoning [100]. Ekinci et al. studied 31 battery 
factory workers (stratified into groups, with no statistically significant age difference, based on potential exposure) and 15 healthy volunteers who underwent blood mercury level testing. There was a correlation between presumed exposure and measured blood mercury levels. Higher blood mercury levels were statistically associated with thinner retinal nerve fibre layer, choroid, and macula, and inversely associated with BCVA and colour vision scores. All these associations showed a dose response relationship [92].

Mercury has also been linked to pseudoexfoliation. Pseudoexfoliation syndrome is a systemic disease, characterised by the accumulation of amyloid-like proteins in many organs including the eye, where it impairs aqueous drainage, and may result in high IOP and glaucoma. Heavy metals have been implicated in the other amyloid-mediated neurological diseases such as Alzheimer's, as has been discussed earlier. Mercury permanently inhibits selenoenzymes, which act as a protective mechanism against oxidative stress [101]. Ceylan et al. found significantly raised blood mercury levels in patients with pseudoexfoliation syndrome and suggested that high mercury levels, even below toxic levels, may contribute to increased deposition of pseudoexfoliation material due to decreased antioxidant activity in tissues. Further investigation into how mercury exposure may influence the structure and function of the eye, and the ways in which it may contribute the development of glaucoma, is therefore warranted [102].

\section{Methods for prevention}

Risk factors for heavy metal toxicity include industrial or occupational exposure, consumption of tinned fish, and the use of alternative medicines. Control of exposure through legislation and public health education is in place in most industrialised nations. Heavy metal exposure can be assessed through analysis of hair, urine, and serum samples. Bone levels are used to assess lead exposure. Argun et al. have described a method of cadmium urinary assays using microelectrodes [103]. The method described was sensitive and of use in identifying exposure [103]. Serum blood tests can be relatively inexpensive, with a serum lead blood test as cheap as US\$10 [104]. Environmental sample assays offer a method of testing possible sources of toxicity. Santos and Azevedo described a method for testing cadmium levels in water, using ultrasound-assisted emulsification microextraction [105]. Zeng et al. have explored the use of a spectrometry kit to test for mercury and silver levels targeted at identification of contamination of water in emergency situations and was shown to be sensitive and inexpensive [106].

Prevention of exposure of the population to heavy metals is achieved by regulation of food and water, review of occupational risk, and investigation of cases of heavy metal poisoning. In the United Kingdom agencies such as the Department for Environment, Food \& Rural Affairs and the Food Standards Agency are responsible for preventing heavy metal contamination of agricultural land and food respectively. In the United States of America, the Agency for Toxic Substances and Disease Registry along with state public health organisations are responsible for the prevention of heavy metal contamination and investigation of cases. Tetraethyl lead levels in automotive fuel were reduced in the 1970s under the U.S. Clean Air Act, which mandated phased annual reductions in lead gasoline levels. In 2017, Algeria, Yemen, and Iraq were the only countries with widespread use of leaded fuel. In USA, the removal of lead from petrol between 1976 and 1995 resulted in a 90\% reduction in mean blood lead level (US Department of Health and Human Services, 1997) [107]. Similar effects were recorded in Western Europe, Australia, Canada, New Zealand, and South Africa [108]. Given the plausible link between heavy metals and glaucoma, the management of the population's cumulative heavy metal exposure may have a role in the prevention of POAG.

\section{Future directions}

Current evidence points to heavy metal toxicity as a potential modifiable risk factor for glaucoma. We feel that the high rate of normal pressure glaucoma in Japan coupled with the documented high cadmium intake in Japan warrants urgent examination [109]. The role of heavy metals in many diseases, which affect millions of people worldwide, has been discussed in this paper. These diseases have pathological pathways in common with those responsible for damage of the optic nerve in glaucoma. Future research should focus on clarifying the specific role of the heavy metals in the pathogenesis of glaucoma, furthering our understanding of the disease, and plausibly offering significant benefit for patients through identification of new modifiable risk factors.

Funding International Glaucoma Association, Ashford, Kent, UK. The Richard Desmond Charitable Trust (via Fight for Sight), London, UK. The funders had no input into the study design, the interpretation of data, the writing of the report, nor in the decision to submit the article for publication.

\section{Compliance with ethical standards}

Conflict of interest The authors declare that they have no conflict of interest.

Publisher's note Springer Nature remains neutral with regard to jurisdictional claims in published maps and institutional affiliations. 


\section{References}

1. Foster PJ, Buhrmann R, Quigley HA, Johnson GJ. The definition and classification of glaucoma in prevalence surveys. $\mathrm{Br} \mathrm{J}$ Ophthalmol. 2002;86:238-42.

2. Quigley HA, Broman AT. The number of people with glaucoma worldwide in 2010 and 2020. Br J Ophthalmol. 2006;90:262-7.

3. Garway-Heath DF, Crabb DP, Bunce C, Lascaratos G, Amalfitano F, Anand N, et al. Latanoprost for open-angle glaucoma (UKGTS): a randomised, multicentre, placebo-controlled trial. Lancet. 2015;385:1295-304.

4. Leske MC, Heijl A, Hyman L, Bengtsson B, Group EMGT, Early Manifest Glaucoma Trial: design and baseline data. Ophthalmology. 1999;106:2144-53.

5. Khawaja AP, Bailey JNC, Wareham NJ, Scott RA, Simcoe M, Igo RP, et al. Genome-wide analyses identify 68 new loci associated with intraocular pressure and improve risk prediction for primary open-angle glaucoma. Nat Genet. 2018;50:778.

6. Kapetanakis VV, Chan MP, Foster PJ, Cook DG, Owen CG, Rudnicka AR. Global variations and time trends in the prevalence of primary open angle glaucoma (POAG): a systematic review and meta-analysis. Br J Ophthalmol. 2016;100:86-93.

7. Weinreb RN, Khaw PT. Primary open-angle glaucoma. Lancet. 2004;363:1711-20.

8. Chaturvedi N, Hedley-Whyte ET, Dreyer EB. Lateral geniculate nucleus in glaucoma. Am J Ophthalmol. 1993;116:182-8.

9. Chen WW, Wang N, Cai S, Fang Z, Yu M, Wu Q, et al. Structural brain abnormalities in patients with primary openangle glaucoma: a study with 3T MR imaging. Invest Ophthalmol Vis Sci. 2013;54:545-54.

10. Crish SD, Sappington RM, Inman DM, Horner PJ, Calkins DJ. Distal axonopathy with structural persistence in glaucomatous neurodegeneration. Proc Natl Acad Sci USA. 2010;107:5196-201.

11. Lawlor M, Danesh-Meyer H, Levin LA, Davagnanam I, De Vita E, Plant GT. Glaucoma and the brain: trans-synaptic degeneration, structural change, and implications for neuroprotection. Survey of ophthalmology. 2018;63:296-306.

12. Sivak JM. The aging eye: common degenerative mechanisms between the Alzheimer's brain and retinal diseasecommon degenerative mechanisms between brain and retina. Investig Ophthalmol Vis Sci. 2013;54:871-80.

13. Danesh-Meyer HV, Levin LA. Glaucoma as a neurodegenerative disease. J Neuroophthalmol. 2015;35:S22-8.

14. Gupta N, Yücel YH. Glaucoma as a neurodegenerative disease. Curr Opin Ophthalmol. 2007;18:110-4.

15. Hinton DR, Sadun AA, Blanks JC, Miller CA. Optic-nerve degeneration in Alzheimer's disease. $\mathrm{N}$ Engl $\mathrm{J}$ Med. 1986;315:485-7.

16. Ghiso JA, Doudevski I, Ritch R, Rostagno AA. Alzheimer's disease and glaucoma: mechanistic similarities and differences. J Glaucoma. 2013;22:S36.

17. Keenan TD, Goldacre R, Goldacre MJ. Associations between primary open angle glaucoma, Alzheimer's disease and vascular dementia: record linkage study. $\mathrm{Br} \quad \mathrm{J}$ Ophthalmol. 2015;99:524-7.

18. Noble W, Hanger DP, Miller CC, Lovestone S. The importance of tau phosphorylation for neurodegenerative diseases. Frontiers in neurology. 2013;4:83.

19. Carreras FJ. Pathogenesis of glaucoma: how to prevent ganglion cell from axonal destruction? Neural Regen Res. 2014;9:2046.

20. Carreras FJ. Glaucoma and amyotrophic lateral sclerosis, two kindred diseases? Neural Regen Res. 2016;11:1415.

21. Li Y, Li D, Ying X, Khaw PT, Raisman G. An energy theory of glaucoma. Glia. 2015;63:1537-52.
22. Couratier P, Corcia P, Lautrette G, Nicol M, Preux P-M, Marin B. Epidemiology of amyotrophic lateral sclerosis: a review of literature. Rev Neurol. 2016;172:37-45.

23. Maruyama H, Morino H, Ito H, Izumi Y, Kato H, Watanabe Y, et al. Mutations of optineurin in amyotrophic lateral sclerosis. Nature. 2010;465:223-6.

24. Rezaie T, Child A, Hitchings R, Brice G, Miller L, Coca-Prados $\mathrm{M}$, et al. Adult-onset primary open-angle glaucoma caused by mutations in optineurin. Science. 2002;295:1077-9.

25. Lee HJ, Park MK, Seo YR. Pathogenic mechanisms of heavy metal induced-Alzheimer's disease. Toxicol Environ Health Sci. 2018;10:1-10.

26. Park J-H, Lee D-W, Park KS, Joung H. Serum trace metal levels in Alzheimer's disease and normal control groups. Am J Alzheimers Dis Dement. 2014;29:76-83.

27. Chen L, Liu L, Huang S. Cadmium activates the mitogenactivated protein kinase (MAPK) pathway via induction of reactive oxygen species and inhibition of protein phosphatases 2A and 5. Free Radic Biol Med. 2008;45:1035-44.

28. Chen S, Xu Y, Xu B, Guo M, Zhang Z, Liu L, et al. CaMKII is involved in cadmium activation of MAPK and mTOR pathways leading to neuronal cell death. J Neurochem. 2011;119:1108-18.

29. Lopez E, Figueroa S, Oset-Gasque MJ, Gonzalez MP. Apoptosis and necrosis: two distinct events induced by cadmium in cortical neurons in culture. Br J Pharm. 2003;138:901-11.

30. Syme CD, Viles JH. Solution 1H NMR investigation of $\mathrm{Zn} 2+$ and $\mathrm{Cd} 2+$ binding to amyloid-beta peptide $(\mathrm{A} \beta)$ of Alzheimer's disease. Biochim Biophys Acta. 2006;1764:246-56.

31. Jiang L-F, Yao T-M, Zhu Z-L, Wang C, Ji L-N. Impacts of Cd (II) on the conformation and self-aggregation of Alzheimer's tau fragment corresponding to the third repeat of microtubulebinding domain. Biochim Biophys Acta. 2007;1774:1414-21.

32. Min J, Min K. Blood cadmium levels and Alzheimer's disease mortality risk in older US adults. Environ Health. 2016;15:69.

33. Chin-Chan M, Navarro-Yepes J, Quintanilla-Vega B. Environmental pollutants as risk factors for neurodegenerative disorders: Alzheimer and Parkinson diseases. Front Cell Neurosci. 2015;9:124.

34. Jang M, Kim S-A, Park EY, Lee KY, Shin S, Kim JE, et al. The association between heavy metals in food and Alzheimer's disease in Korean elderly people. FASEB J. 2013;27:616.4-616.4.

35. Fang F, Kwee LC, Allen KD, Umbach DM, Ye W, Watson M, et al. Association between blood lead and the risk of amyotrophic lateral sclerosis. Am J Epidemiol. 2010;171:1126-33.

36. Roos PM, Vesterberg O, Syversen T, Flaten TP, Nordberg M. Metal concentrations in cerebrospinal fluid and blood plasma from patients with amyotrophic lateral sclerosis. Biol Trace Elem Res. 2013;151:159-70.

37. Bar-Sela S, Reingold S, Richter ED. Amyotrophic lateral sclerosis in a battery-factory worker exposed to cadmium. Int $\mathbf{J}$ Occup Environ Health. 2001;7:109-12.

38. Vinceti M, Filippini T, Mandrioli J, Violi F, Bargellini A, Weuve J, Fini N, Grill P, Michalke B. Lead, cadmium and mercury in cerebrospinal fluid and risk of amyotrophic lateral sclerosis: A case-control study. Journal of Trace Elements in Medicine and Biology. 2017;43:121-5.

39. D'Amico E, Factor-Litvak P, Santella RM, Mitsumoto H. Clinical perspective on oxidative stress in sporadic amyotrophic lateral sclerosis. Free Radic Biol Med. 2013;65:509-27.

40. Kamel F, Umbach DM, Munsat TL, Shefner JM, Hu H, Sandler DP. Lead exposure and amyotrophic lateral sclerosis. Epidemiology. 2002;13:311-9.

41. Cabell L, Ferguson C, Luginbill D, Kern M, Weingart A, Audesirk G. Differential induction of heme oxygenase and other stress proteins in cultured hippocampal astrocytes and neurons by inorganic lead. Toxicol Appl Pharm. 2004;198:49-60. 
42. Qian Y, Zheng Y, Ramos KS, Tiffany-Castiglioni E. The involvement of copper transporter in lead-induced oxidative stress in astroglia. Neurochem Res. 2005;30:429-38.

43. Brown RC, Lockwood AH, Sonawane BR. Neurodegenerative diseases: an overview of environmental risk factors. Environ Health Perspect. 2005;113:1250-6.

44. Gibb WR, Lees A. The relevance of the Lewy body to the pathogenesis of idiopathic Parkinson's disease. J Neurol Neurosurg Psychiatry. 1988;51:745-52.

45. Kuhn W, Winkel R, Woitalla D, Meves S, Przuntek H, Muller T. High prevalence of parkinsonism after occupational exposure to lead-sulfate batteries. Neurology. 1998;50:1885-6.

46. Coon S, Stark A, Peterson E, Gloi A, Kortsha G, Pounds J, et al. Whole-body lifetime occupational lead exposure and risk of Parkinson's disease. Environ Health Perspect. 2006;114:1872-6.

47. Gorell JM, Peterson EL, Rybicki BA, Johnson CC. Multiple risk factors for Parkinson's disease. J Neurol Sci. 2004;217:169-74.

48. Perl DP, Olanow CW. The neuropathology of manganeseinduced Parkinsonism. J Neuropathol Exp Neurol. 2007;66:675-82.

49. Dehghanifiroozabadi M, Noferesti P, Amirabadizadeh A, Nakhaee S, Aaseth J, Noorbakhsh F, et al. Blood lead levels and multiple sclerosis: a case-control study. Mult Scler Relat Disord. 2019;27:151-5

50. Aliomrani M, Sahraian MA, Shirkhanloo H, Sharifzadeh M, Khoshayand MR, Ghahremani MH. Correlation between heavy metal exposure and GSTM1 polymorphism in Iranian multiple sclerosis patients. Neurol Sci. 2017;38:1271-8.

51. Vijaya L, George R, Baskaran M, Arvind H, Raju P, Ramesh $\mathrm{SV}$, et al. Prevalence of primary open-angle glaucoma in an urban south Indian population and comparison with a rural population: the Chennai Glaucoma Study. Ophthalmology. 2008;115:648-654. e1.

52. Garudadri C, Senthil S, Khanna RC, Sannapaneni K, Rao HBL. Prevalence and risk factors for primary glaucomas in adult urban and rural populations in the Andhra Pradesh Eye Disease Study. Ophthalmology. 2010;117:1352-9.

53. Gherardi M, Pontalti F, Vianello G, Antisari LV. Heavy metals in the soil-plant system: monitoring urban and extra-urban parks in the Emilia Romagna Region (Italy). Agrochimica. 2009;53:196-208.

54. Antisari LV, Orsini F, Marchetti L, Vianello G, Gianquinto G. Heavy metal accumulation in vegetables grown in urban gardens. Agron Sustain Dev. 2015;35:1139-47.

55. Apeagyei E, Bank MS, Spengler JD. Distribution of heavy metals in road dust along an urban-rural gradient in Massachusetts. Atmos Environ. 2011;45:2310-23.

56. Shabbaj II, Alghamdi MA, Shamy M, Hassan SK, Alsharif MM, Khoder MI. Risk assessment and implication of human exposure to road dust heavy metals in Jeddah, Saudi Arabia. Int J Environ Res Public Health. 2017;15:36.

57. Apostoli P, Catalani S, Zaghini A, Mariotti A, Poliani PL, Vielmi $\mathrm{V}$, et al. High doses of cobalt induce optic and auditory neuropathy. Exp Toxicol Pathol. 2013;65:719-27.

58. Rizzetti MC, Liberini P, Zarattini G, Catalani S, Pazzaglia U, Apostoli P, et al. Loss of sight and sound. Could it be the hip? Lancet. 2009;373:1052.

59. Bradberry SM, Wilkinson JM, Ferner RE. Systemic toxicity related to metal hip prostheses. Clin Toxicol. 2014;52:837-47.

60. Catalani S, Rizzett MC, Padovani A, Apostoli P. Neurotoxicity of cobalt. Hum Exp Toxicol. 2012;31:421-37.

61. Ng SK, Ebneter A, Gilhotra JS. Hip-implant related chorioretinal cobalt toxicity. Indian J Ophthalmol. 2013;61:35.

62. Vetalice JA. Orthopaedic industry annual report-focus on joint replacement. OrthoKnow. 2012;1-8.
63. Unsworth-Smith T, Khan JC, Khan RJ, Chelva E, Lim CA, Haebich S, Trevenen ML. Impact of Raised Serum Cobalt Levels From Recalled Articular Surface Replacement Hip Prostheses on the Visual Pathway. The Journal of arthroplasty. 2017;32:3147-51.

64. Monies A, Prost M. Experimental studies on lesions of eye tissues in cobalt intoxication. Klin Ocz. 1994;96:135-9.

65. Carelli V, Barboni P, Sadun AA. Mitochondrial ophthalmology. Mitochondrial Med Oxf Inf Healthc. 2006;105-42.

66. Prozialeck WC, Edwards JR, Woods JM. The vascular endothelium as a target of cadmium toxicity. Life Sci. 2006;79:1493-506.

67. Gonzalez-Reimers E, Martín-González C, Galindo-Martín L, Aleman-Valls MR, Velasco-Vázquez J, Arnay-de-la-Rosa M, et al. Lead, cadmium and zinc in hair samples: relationship with dietary habits and urban environment. Biol Trace Elem Res. 2014;157:205-10.

68. Robson TC, Braungardt CB, Rieuwerts J, Worsfold P. Cadmium contamination of agricultural soils and crops resulting from sphalerite weathering. Environ Pollut. 2014;184:283-9.

69. Clarkson TW, Magos L. The toxicology of mercury and its chemical compounds. Crit Rev Toxicol. 2006;36:609-62.

70. Karri V, Schuhmacher M, Kumar V. Heavy metals ( $\mathrm{Pb}, \mathrm{Cd}$, As and $\mathrm{MeHg}$ ) as risk factors for cognitive dysfunction: a general review of metal mixture mechanism in brain. Environ Toxicol Pharm. 2016;48:203-13.

71. Lee SH, Kang EM, Kim GA, Kwak SW, Kim JM, Bae HW, et al. Three toxic heavy metals in open-angle glaucoma with lowteen and high-teen intraocular pressure: a cross-sectional study from South Korea. PLoS ONE. 2016;11:e0164983.

72. Chung HS, Harris A, Evans DW, Kagemann L, Garzozi HJ, Martin B. Vascular aspects in the pathophysiology of glaucomatous optic neuropathy. Surv Ophthalmol. 1999;43:S43-50.

73. Clarkson TW, Magos L, Myers GJ. The toxicology of mercurycurrent exposures and clinical manifestations. N Engl J Med. 2003;2003:1731-7.

74. Murphy TH, Malouf AT, Sastre A, Schnaar RL, Coyle JT. Calcium-dependent glutamate cytotoxicity in a neuronal cell line. Brain Res. 1988;444:325-32.

75. Kaźmierczak K, Malukiewicz G, Lesiewska-Junk H, Laudencka A, Szady-Grad M, Klawe J, et al. Blood plasma levels of microelements in patients with history of optic neuritis. Curr Eye Res. 2014;39:93-8.

76. Stohs SJ, Bagchi D. Oxidative mechanisms in the toxicity of metal ions. Free Radic Biol Med. 1995;18:321-36.

77. Anderson DR. Collaborative normal tension glaucoma study. Curr Opin Ophthalmol. 2003;14:86-90.

78. Fan N, Wang P, Tang L, Liu X. "Ocular Blood Flow and Normal Tension Glaucoma," BioMed Research International, 2015;2015:308505.

79. Kjellström T. Exposure and accumulation of cadmium in populations from Japan, the United States, and Sweden. Environ Health Perspect. 1979;28:169.

80. Iwase A, Suzuki Y, Araie M, Yamamoto T, Abe H, Shirato S, et al. The prevalence of primary open-angle glaucoma in Japanese: the Tajimi Study. Ophthalmology. 2004;111:1641-8.

81. Clarkson TW. Metal toxicity in the central nervous system. Environ Health Perspect. 1987;75:59.

82. Cooper GP, Suszkiw JB, Manalis RS. Heavy metals: effects on synaptic transmission. Neurotoxicology. 1984;5:247-66.

83. Goyer RA. Results of lead research: prenatal exposure and neurological consequences. Environ Health Perspect. 1996;104:1050.

84. Landrigan PJ. Pediatric lead poisoning: is there a threshold? Public Health Rep. 2000;115:530. 
85. Hu H, Rabinowitz M, Smith D. Bone lead as a biological marker in epidemiologic studies of chronic toxicity: conceptual paradigms. Environ Health Perspect. 1998;106:1-8.

86. Cadet JL, Karen IB. "Environmental Toxins And Disorders Of The Nervous System." Neurology and Clinical Neuroscience. Mosby, 2007;1477-88.

87. Arvidson B. Retrograde axonal transport of cadmium in the rat hypoglossal nerve. Neurosci Lett. 1985;62:45-9.

88. Erie JC, Butz JA, Good JA, Erie EA, Burritt MF, Cameron JD. Heavy metal concentrations in human eyes. Am J Ophthalmol. 2005;139:888-93.

89. Goyer RA. Toxic and essential metal interactions. Annu Rev Nutr. 1997;17:37-50.

90. Simons TJ. Lead-calcium interactions in cellular lead toxicity. Neurotoxicology. 1993;14:77-85.

91. Baruah JK, Rasool CG, Bradley WG, Munsat TL. Retrograde axonal transport of lead in rat sciatic nerve. Neurology. 1981;31:612-612.

92. Ekinci M, Ceylan E, Çağatay HH, Keleş S, Altınkaynak H, Kartal B, et al. Occupational exposure to lead decreases macular, choroidal, and retinal nerve fiber layer thickness in industrial battery workers. Curr Eye Res. 2014;39:853-8.

93. Ekinci M, Ceylan E, Keleş S, Çağatay HH, Apil A, Tanyıldız B, et al. Toxic effects of chronic mercury exposure on the retinal nerve fiber layer and macular and choroidal thickness in industrial mercury battery workers. Med Sci Monit. 2014;20:1284.

94. Nelke KH, Mulak M, Łuczak K, Pawlak W, Nienartowicz J, Szumny D, Kochman M, Gerber H Occurrence and Exposure to Lead and Cadmium and Their Environmental Influence on Eyesight. Polish Journal of Environmental Studies. 2015;24.

95. Schaumberg DA, Mendes F, Balaram M, Dana MR, Sparrow D, $\mathrm{Hu} \mathrm{H}$. Accumulated lead exposure and risk of age-related cataract in men. JAMA. 2004;292:2750-4.

96. Yuki K, Dogru M, Imamura Y, Kimura I, Ohtake Y, Tsubota K. Lead accumulation as possible risk factor for primary open-angle glaucoma. Biol Trace Elem Res. 2009;132:1.

97. Albrecht J, Matyja E. Glutamate: a potential mediator of inorganic mercury neurotoxicity. Metab Brain Dis. 1996;11:175-84.

98. Salonen JT, Seppänen K, Lakka TA, Salonen R, Kaplan GA. Mercury accumulation and accelerated progression of carotid atherosclerosis: a population-based prospective 4-year follow-up study in men in eastern Finland. Atherosclerosis. 2000;148:265-73.

99. Mela M, Grötzner SR, Legeay A, Mesmer-Dudons N, Massabuau J-C, Ventura DF, et al. Morphological evidence of neurotoxicity in retina after methylmercury exposure. Neurotoxicology. 2012;33:407-15.

100. Saldana M, Collins CE, Gale R, Backhouse O. Diet-related mercury poisoning resulting in visual loss. $\mathrm{Br} \mathrm{J}$ Ophthalmol. 2006;90:1432-4.

101. Ceylan OM, Demirdöğen BC, Mumcuoğlu T, Aykut O. Evaluation of essential and toxic trace elements in pseudoexfoliation syndrome and pseudoexfoliation glaucoma. Biol Trace Elem Res. 2013;153:28-34.

102. Carocci A, Rovito N, Sinicropi MS, Genchi G. Mercury toxicity and neurodegenerative effects. InReviews of environmental contamination and toxicology. Springer, Cham. p. 1-18. 2014.

103. Argun AA, Banks AM, Merlen G, Tempelman LA, Becker MF, Schuelke T, et al. Highly sensitive detection of urinary cadmium to assess personal exposure. Anal Chim Acta. 2013;773:45-51.

104. Raymond J, Wheeler W, Brown MJ. Lead screening and prevalence of blood lead levels in children aged 1-2 years-Child blood lead surveillance system, United States, 2002-2010 and national health and nutrition examination survey, United States, 1999-2010. Morb Mortal Wkly Rep. 2014;63:36-42.

105. Nunes LS, Lemos VA. Ultrasound-Assisted Emulsification Microextraction in an Online System for Determination of Cadmium in Water and Tea Samples. Journal of AOAC International. 2018;101:1647-52.

106. Zeng Y, Ren J, Shen A, Hu J. Field and pretreatment-free detection of heavy-metal ions in organic polluted water through an alkyne-coded SERS test kit. ACS Appl Mater Interfaces. 2016;8:27772-8.

107. Prevention (CDC C for DC and. Update: blood lead levels-United States, 1991-1994. MMWR Morb Mortal Wkly Rep. 1997;46:141-64.

108. Thomas VM. The elimination of lead in gasoline. Annu Rev Energy Environ. 1995;20:301-24.

109. Ikeda M, Watanabe T, Nakatsuka H, Moriguchi J, Sakuragi S, Ohashi F, et al. Cadmium exposure in general populations in Japan: a review. Food Saf. 2015;3:118-35. 